\title{
Southeast Asian Butterfly Project
}

\author{
Eulàlia Gassó Miracle ${ }^{\ddagger}$, Tina Loo Lax $^{\ddagger}$ Caspers ${ }^{\ddagger}$ \\ ‡ Naturalis Biodiversity Center, Leiden, Netherlands
}

Corresponding author: Max Caspers (max.caspers@naturalis.nl)

Received: 01 May 2018 | Published: 15 Jun 2018

Citation: Gassó Miracle E, Loo T, Caspers M (2018) Southeast Asian Butterfly Project. Biodiversity Information Science and Standards 2: e26319. https://doi.org/10.3897/biss.2.26319

\section{Abstract}

Butterflies are important ecosystem components. They play a major role in pollination, are preyed upon and parasitized by other species, and because of their specific habitat requirements, populations can change quickly and are widely regarded as sensitive environmental indicators, being used to assess factors ranging from climate change to land management. So in addition to their enormous aesthetic appeal and educational value to the layperson, they are important to the scientific community in investigating pressing climate change and biodiversity issues.

While attention to and knowledge of butterflies in western countries is significant, this is not necessarily the case for species-rich tropical areas. Naturalis Biodiversity Center possesses a world-class collection of Southeast Asian butterflies, Indonesian specimens in particular, and would like to bridge this geographic gap in knowledge by embarking on a five-year project to establish an online presence of Southeast Asian butterflies. We hope to establish a consortium of interested international museums and institutes to join us in documenting species-level natural histories, distribution and occurrence data, and photos. The data we will be using will come from literature, digitized collections and observations. Ultimately, we hope to also develop a species identification app, provide links to Red List species protection data, serve as an online field guide for butterfly enthusiasts, and promote and stimulate European Union (EU) and Southeast Asian collection digitization. We will begin this year with a pilot project limited to swallowtails (Papilionidae) in our initial effort to provide an online resource of Southeast Asian butterflies for scientists, educators and laypersons alike. 


\section{Keywords}

butterflies, collections, digitization, online knowledge system, image recognition

\section{Presenting author}

Max Caspers

\section{Presented at}

SPNHC, Digitisation and Collections Data (Poster) 